$1-1-2013$

\title{
Aortic dissection presenting as gait disturbance: a case report.
}

\author{
Michael Estreicher \\ Thomas Jefferson University \\ Joseph Portale \\ Thomas Jefferson University \\ Bernard Lopez \\ Thomas Jefferson University
}

Follow this and additional works at: https://jdc.jefferson.edu/emfp

Part of the Emergency Medicine Commons

Let us know how access to this document benefits you

\section{Recommended Citation}

Estreicher, Michael; Portale, Joseph; and Lopez, Bernard, "Aortic dissection presenting as gait disturbance: a case report." (2013). Department of Emergency Medicine Faculty Papers. Paper 16.

https://jdc.jefferson.edu/emfp/16

This Article is brought to you for free and open access by the Jefferson Digital Commons. The Jefferson Digital Commons is a service of Thomas Jefferson University's Center for Teaching and Learning (CTL). The Commons is a showcase for Jefferson books and journals, peer-reviewed scholarly publications, unique historical collections from the University archives, and teaching tools. The Jefferson Digital Commons allows researchers and interested readers anywhere in the world to learn about and keep up to date with Jefferson scholarship. This article has been accepted for inclusion in Department of Emergency Medicine Faculty Papers by an authorized administrator of the Jefferson Digital Commons. For more information, please contact: JeffersonDigitalCommons@jefferson.edu. 


\title{
As submitted to:
}

\section{The American Journal of Emergency Medicine}

\author{
And later published as:
}

\section{Aortic dissection presenting as gait disturbance: a case report \\ Case Report}

\author{
Volume 31, Issue 1, January 2013, Pages: 269.e1-269.e2
}

\section{DOI: http://dx.doi.org/10.1016/j.ajem.2012.04.029}

\author{
Michael Estreicher, MD, Joseph Portale, MD, Bernard Lopez, MD, BS \\ Department of Emergency Medicine, Thomas Jefferson University Hospital, \\ Philadelphia, PA 19102, USA
}

\begin{abstract}
:
Emergency medicine dogma traditionally teaches that aortic dissection presents as tearing chest pain, radiating to the back. This case report describes a 55 year old woman presenting with a left homonymous hemianopsia and resultant gait disturbance. Initial head CT demonstrated a right parietal infarct, and chest radiograph demonstrated a markedly widened mediastinum. Acute Stanford Type A aortic dissection was subsequently confirmed. This report provides further
\end{abstract}


evidence for atypical, painless presentations of aortic dissection. Given recent literature on the increasing prevalence of painless dissection, the disease entity should be included in the differential diagnosis for stroke, and a simple portable chest x-ray should always be obtained prior to administering thrombolytics.

\section{Introduction:}

Aortic dissection (AD) is a life threatening emergency. A 2011 report estimates an incidence of 3-4 cases per 100,000 (1). Typical presentation is tearing chest pain, radiating to the back. Traditionally, good outcomes are associated with prompt diagnosis followed by early intervention. However, the true prevalence of AD may be underestimated given reports of atypical presentations, often described as painless or silent $\mathrm{AD}$. This article describes painless $\mathrm{AD}$ in a woman presenting with isolated neurological complaints.

\section{Case Report:}

A 55 year old African-American woman presented to the Emergency Department (ED) complaining of new onset difficulty with "depth perception" for one week. She had no headache at presentation, though recalled a headache that resolved spontaneously when her symptoms began. She denied all other complaints. She had a past medical history of hypertension and medication non-compliance due to loss of health insurance. She reported no significant family or social history.

On arrival, blood pressure was 223/133 mm Hg, heart rate 126 beats per minute, oxygen saturation $98 \%$ on room air, and temperature 97.3 degrees Fahrenheit. On exam, the patient was 
alert and oriented, in no acute distress. Cardiac exam demonstrated a harsh systolic ejection murmur, which she stated "I've had my whole life." Breath sounds were clear and equal bilaterally. Neurologic exam demonstrated left homonymous hemianopsia. Cranial nerves were otherwise intact. Motor, sensory, and cerebellar exams were normal.

Head CT demonstrated an age-indeterminant infarct within the right parietal lobe, middle cerebral artery territory with small petechial hemorrhage (Figure 1), consistent with the neurologic exam. The patient was admitted to the stroke unit, having her blood pressure and heart rate appropriately controlled in the ED. No chest x-ray was obtained.

Inpatient work-up included a routine echocardiogram, which demonstrated a dilated ascending aorta to 5.5 centimeters with a dissection flap abutting the valve leaflets, communicating with the left ventricle; a Stanford Type A dissection. Chest x-ray during initial inpatient workup demonstrated a widened mediastinum and dilated ascending aorta (Figure 2). On $\mathrm{CT}$ angiogram, the $\mathrm{AD}$ was noted to extend into the origin of right common carotid artery with the large pseudolumen containing thrombus.

During her hospitalization, the patient remained hemodynamically stable without chest or back pain and with no evolution of her embolic stroke or dissection. Given the stable nature of the dissection and stroke, surgery to correct the dissection was delayed for two weeks. The patient underwent aortic root and hemiarch replacement without complication and was discharged in stable condition.

\section{Discussion:}

Acquired and genetic risk factors for $\mathrm{AD}$ are well documented. They contribute to intimal 
disruption, which becomes a dissection when blood passes into the intimal space and creates a false lumen. In a International Registry of Acute Aortic Dissection (IRAD) review of 464 patients , hypertension (72\%) was the most common risk factor, followed by atherosclerosis (31\%), known aortic aneurysm (16.1\%), prior AD (6.4\%), diabetes (5.1\%) and Marfan syndrome (4.9\%). Additionally, chest pain (72.7\%) and back pain (53.2\%) were the two most common locations for pain on presentation. Aortic insufficiency murmur was found in $31.6 \%$ and pulse deficit in $15.1 \%$ (2). Our patient complained of no chest or back pain on repeated detailed history. Furthermore, her presentation was consistent with a simple cerebrovascular accident (CVA).

One of the earliest descriptions of silent AD was by Hoskin and Gardner in 1942 (3). More recent descriptions include varied symptomatology, including syncope (4), crossed hemiparesis (5), left hemiparesis (6), transient locked-in syndrome (7), headache (8), and superior vena cava syndrome (9). The presumed pathophysiology for these findings is thromboembolism resulting from an intimal flap, as in our patient. It is still unclear, however, why these presentations lack pain. Some theorize that slow dissection may not cause pain or that sparing of intercostal, lumbar, and splanchnic vessels results in painless dissection (10).

Park et al reported increased mortality (33.3\% v.s. $23.2 \%)$ and Imamura et al reported more unfavorable functional outcomes when comparing painless to painful acute AD (11,12). In the latter study, there was a higher rate of neurologic sequelae, including persistent disturbance of consciousness, syncope, and focal neurologic deficit as presenting symptoms in the painless group compared to the painful group, but no difference in mortality. Recent studies demonstrating worse outcomes in patients with painless AD have caused heightened awareness 
in patients with hypertension and an abnormal cardiac exam. It may, therefore, be prudent to add $\mathrm{AD}$ to the differential diagnosis for patients presenting with symptoms consistent with a CVA.

\section{Conclusion:}

Our case contributes to the evidence that the prototypical tearing chest pain radiating to the back is not always present in an acute AD. Furthermore, it raises questions regarding the management of CVA and the use of thrombolytics in the Emergency Department. Considering the potentially high morbidity associated with thrombolytics, a simple portable chest x-ray should be added to the ED workup prior to administration. Prospective randomized studies will be needed to further assess the true incidence of painless $\mathrm{AD}$ and its $\mathrm{ED}$ management.

\section{References:}

1. Lemaire SA, Russell L. Epidemiology of thoracic aortic dissection. Nature Reviews Cardiology. 2011;8:103-113

2. Hagan PG, Nienaber CA, Isselbacher EM, et al. The Internation Registry of Acute Aortic Dissection (IRAD): New Insights Into an Old Disease. JAMA. 2000;283: 897-903.

3. Hoskin J, Gardner F. Silent Dissection of the Aorta. Br Heart J. 1946 July;8(3):141-146

4. Young J, Herd AM. Painless acute aortic dissection and rupture presenting as syncope. J Emerg Med. 2002;22(2):171-174

5. Pikija S, Cvetko D, Kostanjevec R, et al. Aortic dissection presenting as crossed hemiparesis. Neurologist. 2010;16(2):113-114. 
6. Morita S, Shibata M, Nakagawa Y, et al. Painless acute aortic dissection with a left hemiparesis. Neurocrit Care. 2006;4(3): 234-236.

7. Nadour W, Goldwasser B, Biederman RW, et al. Silent aortic dissection presenting as transient locked-in syndrome. Tex Heart Inst J. 2008;35(3):359-361

8. Stollberger C, Finsterer J, Fousek C, et al. Headache as the initial manifestation of acute aortic dissection type A. Cephalalgia. 1998;18(8):583-584.

9. Link MS, Pietrzak MP. Aortic dissection presenting as superior vena cava syndrom. Am J Emerg Med. 1994;12(3):326-328

10. Gerber O, Heyer EJ, Vieux U. Painless dissections of the aorta presenting as acute neurologic syndromes. Stroke. 1986;17:644-647.

11. Park SW, Hutchinson S, Mehta R, et al. Association of painless acute aortic dissection with increased mortality. Mayo Clin Proc. 2004;79(10):1252-1257

12. Imamura H, Sekiguchi Y, Iwashita T, et al. Painless acute aortic dissection--diagnostic, prognostic, and clinical implications. Circ J. 2011;75: 59-66. 